Future relevance The project evolves on an annual basis with a different activity inside. There is a potential for future collaborative developments but these will be dependent on funding. Post is currently funded by Macmillan Cancer Support.

\section{P-39 ENABLING YOUNG PEOPLE TO EXPLORE THEIR UNDERSTANDING OF DEATH THROUGH DRAMA}

Sarah Popplestone-Helm. St Richard's Hospice, Worcester, UK. Daniel Morgan

\subsection{6/bmjspcare-2016-001245.63}

"Give sorrow words; the grief that does not speak knits up the oer wrought heart and bids it break." - William Shakespeare, Macbeth Act IV Scene III

The hospice received funding from the local Clinical Commissioning Group to support schools in South Worcestershire. The aim was to enable a more balanced and healthier view of death, dying and bereavement within the school environment.

Using part of this grant the hospice worked in partnership with a local senior school, to develop Year 11 pupils' knowledge and understanding of death and bereavement through drama; they planned to produce an assessed performance for their GCSE.

Fifteen Year 11 pupils visited the hospice; they had a formal talk on hospice work and met with a bereaved person and asked questions regarding the family's experience. A comprehensive tour of the building gave them insight into the work undertaken and of the environment.

During the visit, they wrote down one word describing their expectations. They were asked to repeat the exercise at the end of the visit. It was clear that their expectations were different from the reality of hospice work.

The final production included stories that the pupils had heard whilst at the hospice, the wedding of a patient, the creation of a memory box for a child, the importance of honesty and trust. All of these themes were explored through drama in a sensitive and informed way.

This has become an annual event. This year's cohort of drama students will be considering the Hospice Care Week on 'Connecting Care'. The potential for an increased understanding of death within the younger generation is crucial to the demystifying of hospice work. A more balanced and healthier view of death, dying and bereavement is to be encouraged.

\section{P-40 'MEMORY IS THE SCRIBE OF THE SOUL' (ARISTOTLE): PATIENT WELLBEING AND THE HOSPICE POET}

Phil Isherwood. Bolton Hospice, UK

\subsection{6/bmjspcare-2016-001245.64}

A hospice poet will present his distinctive approach to writing poetry which has been developed over five years, writing poetry based on conversations with, and the creative artwork of, hospice patients. His creative $\mathrm{PhD}$ research at the University of Bolton has established specific working methods as a writer, producing over 200 poems, and identified particular qualities in poetry of special value relating to transcendence, wonder and otherness.
Support for the approach will be presented with particular reference to narrative identity and creativity, utilising the potential of poetry to provide a creative work based on a patient's own life. This will be argued as supportive to personal significance and identity, valuable to patient wellbeing and as memorial art and legacy.

Furthermore the poet, and the poetry produced, supports the hospice principle of 'being with'. Particular aspects of creativity and mystery will be highlighted as a way to access transcendence - arguing value for such creative representation of a patient's life at a time when a more simplistic presentation of meaning and understanding may prove inadequate. Examples of poetry will be used relating to personal narratives, to creative work by patients and also work based on patient 'memory boxes'.

Further key issues will be raised regarding the role of the poet and the case made for this approach to be fully accepted as psycho-social support and integrated within the end-of-life care aims regarding a 'good death'. The approach is especially appropriate for volunteer and community partnerships to strengthen the creative and different side to hospice care and patient wellbeing.

\section{P-41 EVALUATION OF AROMA STICKS FOR ANXIETY AS AN EXTENSION OF AROMATHERAPY TREATMENT}

Sharon Penny. Princess Alice Hospice, Esher, UK

\subsection{6/bmjspcare-2016-001245.65}

Background Anxiety is a common problem within palliative care whether with a cancer diagnosis or other life- limiting disease. We wanted to look at how patients could have autonomy to relieve anxiety in a non-medical way. We were aware other hospices and hospitals were using aroma sticks with good effect (Dyer et al., 2013).

Aim To explore the impact of aroma stick use on patients' anxiety.

Method Patients were selected by the multi-disciplinary team. Subject to consent, patients were asked to complete a questionnaire asking them about use of aroma sticks (whether they used them, what they liked or disliked about them and what benefit they may have felt). A visual analogue scale $(0=$ calm and $10=$ panic) explored patient anxiety level. Patients could choose a preference from four blends of essential oils. The patient was then instructed how to use the aroma stick when they were feeling anxious at baseline. Then at seven and 14 days the patients repeated the questionnaire and anxiety scale. We aimed for a minimum of 10 patient completed questionnaires.

Results 26 patients took part, six were lost to follow up. Seven key themes were highlighted the top three being; $71.4 \%$ felt more relaxed; 57\% felt stress levels reduced; and 50\% felt mood had improved and felt better able to cope. The ease of use and the fact the aroma stick was small enough to keep on their person was a contributing factor.

Conclusion Following the results of these findings, we are using aroma sticks as an extension of our aromatherapy service across our patient base for anxiety, nausea, and breathlessness. The most important finding was the patient's autonomy to help them with a non-medical intervention. 